\title{
GCU
}

Glasgow Caledonian

University

University for the Common Good

\section{Some video games can increase the player's creativity}

Moffat, David C.; Crombie, William; Shabalina, Olga

Published in:

International Journal of Game-Based Learning

DOI:

10.4018/IJGBL.2017040103

Publication date:

2017

Document Version

Publisher's PDF, also known as Version of record

Link to publication in ResearchOnline

Citation for published version (Harvard):

Moffat, DC, Crombie, W \& Shabalina, O 2017, 'Some video games can increase the player's creativity', International Journal of Game-Based Learning, vol. 7, no. 2. https://doi.org/10.4018/IJGBL.2017040103

\section{General rights}

Copyright and moral rights for the publications made accessible in the public portal are retained by the authors and/or other copyright owners and it is a condition of accessing publications that users recognise and abide by the legal requirements associated with these rights.

Take down policy

If you believe that this document breaches copyright please view our takedown policy at https://edshare.gcu.ac.uk/id/eprint/5179 for details of how to contact us. 


\title{
Some Video Games Can Increase the Player's Creativity
}

\author{
David C. Moffat, Glasgow Caledonian University, Digital Design Technologies, Glasgow, United Kingdom \\ William Crombie, Glasgow Caledonian University, Digital Design Technologies, Glasgow, United Kingdom \\ Olga Shabalina, Volgograd State Technical University, CAD Department, Volgograd, Russia
}

\begin{abstract}
It is said that playing video games might make people more creative. There is some evidence of an association, but no so far general theory about any psychological causes, or other key factors. In this study, we test the possibility that different sorts of video games may have different effects, on different types of creativity; or none at all. Three games were tested, including a sandbox and a puzzle game (Minecraft and Portal 2), and creativity was measured by the Torrance Tests of Creative Thinking (TTCT). The games were hound to have different effects, and on only some measures. We discuss possible accounts for these results, and offer practical suggestions to better control such studies in future. The strongest and most surprising result was that one particular form of creativity, flexibility, was affected much more than others. This finding awaits a theoretical explanation; but in the meantime, the implication is that video games could be used to put students into a more creative state of mind, which may be useful for their learning.
\end{abstract}

\section{KEYWORDS}

Creativity, Divergent Thinking, Enjoyment, Game Genre, Puzzle Games, Sandbox Games, Torrance Tests of Creative Thinking (TTCT), Video Games

\section{INTRODUCTION}

Serious games and game-based learning (GBL) are increasingly used to teach school subjects like history and arithmetic. They can convey curriculum knowledge, or motivate students to learn the subject, or encourage them to practice their skills. As well as specific subject knowledge, however, students also need to develop more general cognitive skills. One example of this is creativity, which is recognised as increasingly important in the modern economy. It would be very beneficial to students, and society at large, if we could find reliable ways to encourage and develop creativity in the education system.

Video games might be one way to do this. There is already a connection between games and creativity, in the concept of flow. This concept was originally derived by Csikszentmihalyi (1996) from his study of highly creative people; but it is now routinely used by game designers to describe the mental state they aim to achieve in their players. While many types or genres of games may induce a state of flow, however, it might not be the case that they all have the same effects on creativity. 
Apart from the discovery that flow is often associated with it, creativity is generally characterised as or defined to be the cognitive capacity to generate novel ideas that are valuable in some domain, but that are not obvious to most people (Amabile, \& Csikszentmihalyi, both 1996). It can take on an exploratory character, such as when jazz musicians improvise for example; or creativity may be evident in solving problems, such as in scientific or engineering domains.

In the following, we report an experiment to see if different kinds of game, including one with exploratory gameplay (a sandbox game), and another with problem solving (a puzzle game), would have a measurable effect on players' creativity. As a control, we had a third game also, which was an FPS game (first-person shooter), and which was not expected to have much effect, if at all.

The aim was not to see if there would be any long-term or permanent changes wrought. That would be good to achieve, but presumably would be more difficult to establish. In this initial work, then, we aimed only to see if a short-term or temporary effect might be induced. That could already be useful in a classroom situation, such as at the start of an art or music lesson perhaps. In a temporarily heightened state of creativity, the students might do better work; and that could help them to be more confident of their creative powers in future. Such a change in attitude might well outlast the temporary mental change that caused it.

\section{Theories of Creativity and How to Measure It}

Assessing creativity has generated much debate. Cohen (2010) describes creativity as a multipart notion, not a lone entity, with no single comprehensive meaning for creativeness or its measurement. Indeed, given the numerous ways creativity can be applied, Treffinger (2009) indicates that a "one test fits all" approach is unrealistic. However, while there is no single test for creativity currently supported there are several tests for creativity that are well respected such as Guilford's divergent thinking based tests, which are commonly used (Silvia et al, 2009). There is also TTCT: Torrance's test of creative thinking (Neumeister \& Cramond. 2004), which measures divergent thinking: "the ability to find multiple solutions to a problem" (Millar \& Dahl, 2011).

Many varying elements can influence a person's creativity. Lubart et al (2010) for instance state that aggression would affect creative ability, and a person's emotional state (be it happy, sad, angry and so on) can impinge upon their creativity either positively or negatively. Vidal \& Valqui (2009) imply that creative potential can be improved or hindered in multiple ways, in regards to Torrance's research into individual creativity. They also state that "family environment, the educational system, and organisational bureaucracy" can all be obstacles that may reduce one's creative potential.

The age of a person also has an influence on their creative potential: "creativity is often obvious in young children, but may be harder to find in older children and adults." Sternberg (2006) goes on to suggest that adult creativity is stifled by social expectations of uniformity.

Regarding playfulness in art education, Pitri (2013) suggests it is closely related to creative play. As children usually play more than adults their use of the creative process becomes more effective hence they are evidently more creative. However, Torrance's research into creativity describes being creative as a non-linear process: "individuals are creative and that creativity can be enhanced or blocked" (Vidal \& Valqui, 2009); that regardless of age everyone is able to be creative and that external factors imping upon creativity and its development. Hence being able to encourage creativity in adults would be beneficial: improving business and economic growth for instance.

As more of the population play video games in recent years, the possibility that video games as a medium could be used as a learning tool to enhance creativity is stronger than ever. However, the understanding of certain games and the impact they have on the player is not fully understood. Research has shown that some genres of game provide the player with additional benefits (Glass, Maddox \& Love, 2013; and Eichenbaum, Bavelier \& Green 2014). The notion that games benefit the player's creative ability has not been fully explored in regards to different genres of video game.

In this study, we aim to see if playing video games for as little as a half hour can affect a person's levels of creativity. Furthermore, we investigate the possibility that different genres of video game 
might have differential effects. We ask participants to play one of three different types of game: a puzzle game, a sandbox game, and a first-person shooter game. We hypothesised that if any game genre would increase creativity, it would be the sandbox game, and possibly the puzzle game.

\section{EXPERIMENT}

The aim of this experiment is to evaluate the potential differences in creativity of video game players, after exposure to a specific game genre. This will be realized with a creative test that will be used both before and after the game. The test is based upon divergent thinking theory from Guilford's "structure of the intellect" tests and Torrance's creative thinking tests. Using the principles of both tests, it will evaluate the player's fluency, originality and flexibility.

The use of divergent thinking theory is based on the fact that it is a "very useful estimate for potential creative thought" (Kaufman et al 2008). Both test methods have a wealth of empirical research based on them in regards to creative measurement: hence their use as the foundation for the creativity test to be used in the experiment. Self-assessment methodology was also implemented in the experiment to work in tandem with the creativity test. This is to take measurements of player enjoyment and game familiarity.

\section{The Participants and Games Used}

Participants were young adults aged between eighteen and thirty, taken from the student body by convenience sampling. This was to reflect the general university undergraduate population, because that is the sector which we would one day hope to be able to serve better with teaching interventions informed by the results. We did not select participants on the basis of their familiarity with the games used in the experiment, because we wished to see if relative novices could also benefit from playing a game. We did ask the participants how familiar with the particular games they were, or with other similar games of the same type.

Many creativity training programs and workshops offer multiple sessions of hour or even days in length. These sessions are usually broken down into multiple activities, which commonly last at least 30 minutes. The experiment is designed to see if this minimal length of exposure to the game would work be enough to enhance creative potential.

The games chosen to represent each of the three genres were Serious Sam, Portal-2 and Minecraft. The game Minecraft was chosen to be the sandbox game in the experiment because of its mode where the player can build or destroy whatever they wish.

Portal-2 was chosen to represent the puzzle genre because it is an effective problem solving game, and problem solving is associated with creative ability and potential. The final game, Serious Sam, was chosen to represent the shooter genre. It is a classic FPS game with standard mechanics for this genre, and serves as a control condition, less likely to stimulate creativity.

\section{Types of Creativity to be Tested}

As stated before fluency is one aspect commonly examined in divergent thinking, it features in both Guilford's and Torrance's tests. To measure this aspect, the creativity test used in the experiment will ask the subject to list as many possible uses for an everyday item. Guilford's (1967) work would describe this as a Utility test to gauge fluency; while Torrance would classify it as a self-contained verbal test on fluency (Kaufman et al 2008). Both methods use this test with the fluency of the subject being measured directly by the number of responses given, which Kaufman et al (2008) also implies is a standard way of measuring fluency in most divergent thinking tests.

The measurement of originality can also be found in both Guilford's and Torrance's work. The experiment test will have the subject consider an implausible scenario such as people not needing to eat. This type of test would be described as "consequence" by Guilford and a "just suppose" question by Torrance. Both refer to this type of test as one for measuring originality (Kaufman et al 2008). 
The originality of the subject would be quantified by the unique answers given once, compared to all other subjects' answers in the experiment.

Similarly, the measurement of flexibility is located in Guilford's work in a test of "naming groups" (Kaufman et al 2008). This test would ask the subject to name as many things as possible with a "wheel" or other distinction. The measurement of flexibility is determined by the number of subgroups the examinee thinks of. This indicates their ability to adapt their line of thinking to a given task once obvious options are used.

As Amabile (1996) states: "Assessment of creativity involves subjective judgement." The above methods have been chosen to reduce the amount of subjective judgement required and provide for more replicable results and reliable analysis.

\section{Experimental Procedure}

Participants completed the first version of the creativity test, and then played their allotted game for 30 minutes, on a laptop. For some, the game play was also screen-captured at this time. Once the subjects had completed the 30 minutes of play, they were given the second version of the creativity test to complete, and then a questionnaire about their experience. This experiment is a within-participants design, which gives much more chance of gaining conclusive results, especially in these questions where we anticipate large individual differences. It does take longer however, and for each participant the whole experiment took nearly one hour.

This method allowed the subject's creativity results from the two tests to be directly compared after analysis. It would highlight any correlations or patterns between them, to show whether the genre of game influenced their creative potential. The questionnaire would be analysed in conjunction with the creativity test results to determine if enjoyment is a key factor. The screen recording would be interpreted for player progression in the game levels, and possibly to observe any creative play.

\section{RESULTS}

The experiment was conducted on 21 participants who were split into three groups of seven - one group for each of the three games. These are the components of the results from the experiment. The first component involved the participants completing the creativity test, both before and after playing the relevant game.

The second is the questionnaire that each subject completed after the creativity tests. Finally, there were some screen recordings of the participant's game play. These latter components will be reviewed later to help interpret the numerical data from the creativity tests.

The results are summarised in Table 1, which shows the changes in scores for the three variant measures of creativity: fluency, originality, and flexibility. For each game (by $\mathrm{N}=7$ players), the measures of creativity were taken before and after the game was played.

Table 1. The measures of creativity before and after playing a game

\begin{tabular}{|c|c|c|c|c|c|c|c|}
\hline \multirow{2}{*}{\multicolumn{2}{|c|}{$\begin{array}{l}\text { Game } \\
\text { (Genre) }\end{array}$}} & \multicolumn{2}{|c|}{ Fluency } & \multicolumn{2}{|c|}{ Originality } & \multicolumn{2}{|c|}{ Flexibility } \\
\hline & & Before & After & Before & After & Before & After \\
\hline $\begin{array}{l}\text { Serious Sam } \\
\text { (FPS) }\end{array}$ & $\begin{array}{l}\text { Mean } \\
\text { Std. Dev. }\end{array}$ & $\begin{array}{l}5.57 \\
2.82\end{array}$ & $\begin{array}{l}5.71 \\
3.35\end{array}$ & $\begin{array}{l}3.14 \\
1.35\end{array}$ & $\begin{array}{l}3.71 \\
2.56\end{array}$ & $\begin{array}{l}3.00 \\
2.38\end{array}$ & $\begin{array}{l}6.43 \\
3.26\end{array}$ \\
\hline $\begin{array}{l}\text { Minecraft } \\
\text { (sandbox) }\end{array}$ & $\begin{array}{l}\text { Mean } \\
\text { Std. Dev. }\end{array}$ & $\begin{array}{l}6.00 \\
3.27\end{array}$ & $\begin{array}{l}8.00 \\
3.92\end{array}$ & $\begin{array}{l}2.57 \\
2.23\end{array}$ & $\begin{array}{l}2.43 \\
1.90\end{array}$ & $\begin{array}{l}4.29 \\
2.63\end{array}$ & $\begin{array}{l}6.57 \\
3.05\end{array}$ \\
\hline $\begin{array}{l}\text { Portal } 2 \\
\text { (puzzle) }\end{array}$ & $\begin{array}{l}\text { Mean } \\
\text { Std. Dev. }\end{array}$ & $\begin{array}{l}7.29 \\
5.06\end{array}$ & $\begin{array}{l}8.71 \\
5.77\end{array}$ & $\begin{array}{l}3.14 \\
3.13\end{array}$ & $\begin{array}{l}4.86 \\
2.97\end{array}$ & $\begin{array}{l}4.29 \\
1.80\end{array}$ & $\begin{array}{l}8.57 \\
2.94\end{array}$ \\
\hline TOTAL & $\begin{array}{l}\text { Mean } \\
\text { Std. Dev. }\end{array}$ & $\begin{array}{l}6.29 \\
3.72\end{array}$ & $\begin{array}{l}7.48 \\
4.43\end{array}$ & $\begin{array}{l}2.95 \\
2.25\end{array}$ & $\begin{array}{l}3.67 \\
2.59\end{array}$ & $\begin{array}{l}3.86 \\
2.26\end{array}$ & $\begin{array}{l}7.19 \\
3.09\end{array}$ \\
\hline
\end{tabular}


In order to test the hypotheses that the changes in score were significant (not chance variations), we made some pessimistic assumptions and then conducted a standard statistical test. We assumed that the measures before and after the game were independent samples. That is, we prepared to use a t-test analysis, but without applying it as a repeated measures test. This makes it less likely to get a significant result. We also applied the two-tail form of the test. Furthermore, we did not assume that the two distributions (before and after the game) would have the same variance. Although the t-test assumes a normal distribution, the sample sizes are not large enough to make any formal test for normality sensible. We nevertheless assume normality as a reasonable approximation, given the nature of the creativity tests.

According to the t-test then, when applied to each sample (for each game, and for each type of creativity), we got some significant and mostly non-significant results. For all the games, and for the measures of fluency, and of originality, the results were not statistically significant. However, for the measure of flexibility, the results for the games were significant for Serious Sam $\left(p<0.05^{*}\right.$ with $\mathrm{N}=7, \mathrm{df}=11$, and $\mathrm{t}=2.25)$, and for Portal-2 $(\mathrm{p}<0.01 * *$ with $\mathrm{N}=7, \mathrm{df}=10$, and $\mathrm{t}=3.29)$. Combining the three games, we got an overall score of $\mathrm{t}=3.99(\mathrm{p}<0.001 * * *$ for $\mathrm{N}=21, \mathrm{df}=37)$.

Therefore, we conclude that playing the games made a temporary, highly significant difference to the players' creative aptitude for flexibility.

\section{Creativity Tests Answers}

This section will look into the creativity test results that were gathered from each participant both before and after playing their specific genre of game. It will look at the three key elements of creative ability that the test evaluates. These are fluency (measured by the number of results given), originality (the uniqueness of the answers), and flexibility (the ability to adapt one's line of thinking in subcategories).

The first questions on the creativity test were for measuring fluency in the player. They were based on an object: in these tests, they are a pencil (before playing the game), and cardboard box (afterwards). The subjects were asked to list as many possible uses for each object. The result value was determined by the number of uses given in answers, which varied from short to longer lists. Examples include:

Writing, Scratching head or back, Pointing, Ticking tick sheets, Marking wood before cutting it, Stabbing an intruder, Rubbing out writing if it has an eraser.

Writing utensil, Weapon i.e. shank, Drumstick, Holding something open, End zone markers for paper football, Goal markers for paper rugby, Unit of measurement if inscriptions were made at different increments of length, Lock picker if sharp enough, Catapult for small rubbers and bits of paper when put on the edge of a desk, Barrier if put between two desks if co-workers hate each other, Food if dumb or hungry.

The second question in the creativity tests involved the measurement of originality. This tested the participants in regards to how novel their answers were. To test this the subjects were asked seemingly inconceivable things. For example: "What would happen if people no longer need to sleep (or else breathe)?" The types of answers given varied between the obvious and the very novel. Examples are:

Greater overall productivity, Greater access to public/retail services as there would be more night shift workers. Improved night vision as the average person becomes more attuned to seeing in the dark Lower crime rate as more people are around to see you murder somebody under cover of darkness Last call for alcohol effectively removed as closing times become less necessary More jobs as demand for 9pm-9am workers increases If physical fatigue is eliminated as a result of no longer needing to sleep, then everyone is more energised and probably in better shape so obesity drops. 
There would be no need for bedrooms etc People can stay out partying longer May be expected to work longer hours.

You wouldn't be out of breath when exercising etc. No breathing difficulties so possibly no issues with asthma etc.

The final question in the creativity tests was for the participant's flexibility. This was achieved by asking the subjects to list as many items that contained a certain element as possible. In the two creativity tests the elements were: wheels, and glass. This question identifies different subgroups involving the required element, indicating the participant's creative flexibility. Again, subjects displayed a mixture of results. In the wheels question all participants stated cars and vehicles as obvious answers but the more creative ones identified several other items, such as pulley systems and clocks. That shows greater flexibility. Examples are:

Wheel chairs, cars, vans, lorries, trains, planes, projector tables, tables, chairs, fork-lifts, bikes, motor bikes, skateboards, scooter, go-karts.

Car, bike, clock mechanisms, aircraft, yo-yo, old iPod interface, wheelchair, pulley system.

Cars, houses, cabinets, green houses, vans, lorries, fish tanks, tv, iPad, iPhone, iPod, pictures, ovens, windows, sun glasses, clocks.

It was these latter scores, for flexibility, that showed the significant improvement after playing the games. Contrary to our hypothesis, however, the other scores for creativity did not show any significant difference. We were surprised to see the measures for creativity give such diverse results.

\section{DISCUSSION OF RESULTS AND LIMITATIONS OF THE STUDY}

The experiment was quite small, with 21 participants in all, but only seven in each condition. Although this was enough to deliver some strong results, both in effect size and statistical significance, there is a chance of type-II errors (or missing an effect which a larger study would discover). In particular, the negative results from the sandbox game (Minecraft) might be partially explicable. There were some other observations taken from some of the participants, which help to explain the discrepancy in results between the different creativity scores.

From video recordings of some of the sessions, and from some of the comments by the players in the general questions after the session, it is clear that they were not equally familiar with all the games. In particular, there were some who had not played Minecraft much, and others who were new to Portal-2. Some of them had difficulties in playing their game sessions, and made little progress in some cases. This seemed to have a detrimental effect on their mood, presumably because it was quite frustrating to be unable to get far into the game. It is a strong possibility that their creative performance was hampered by these experiences.

Regarding our hypotheses at the start, we thought that the different games would have differing effects on the players' creativity. In the event, there were differences between the games, but not in the order we had hypothesised. The sandbox game affected creativity less than the others, against expectations. This may well be due to some players finding it difficult to make progress in the game if they are novices. On the other hand, the FPS game (Serious Sam) did significantly affect one measure, and that was the game that we had thought least likely to influence creativity. It was the puzzle game had the most significant effect, which is intuitively reasonable; although many people would expect the sandbox game to be the most effective one. 
To our surprise, there was a highly significant effect with one of the creative scores (for flexibility); and much less so for the others. This is a counterintuitive result, because the different scores for creativity would normally be expected to correlate more. This is probably the most interesting outcome from the experiment. It certainly seems worth investigating further.

Another topic for future research would be the role of emotion or mood as an intermediate variable between game-play and creative performance. Mood might conceivably be an intervening variable in these results.

\section{Further Work and Practical Guidelines}

To follow the encouraging results of this study, it would naturally be worth replicating them in a larger experiment, with more participants; and possibly with different games from the same genres. A similar experiment design would make the results more comparable; but some pragmatic changes could help to control for some of the possibly anomalous ones. If it is true that some players were able to make little progress in the game, that might influence the results in two ways. Firstly, they would not derive much cognitive benefit from the game as some of their time playing it would be wasted. Secondly, they may feel defeated and frustrated by the experience, and if emotional state is a factor in creativity as some suggest, that could also undermine the results.

Accordingly, it would be an idea to either select participants who have already played the game, or give them a separate tutorial first, or select a game with a good quality tutorial mode built into the game which also gives the player the intended experience even as they learn it. These changes carry costs of course, making it more difficult to recruit participants for the experiment, which would also take longer for each one. The validity of the context would also be undermined to an extent, for those who intend (as we did) that the results should inform educational practice in game-based learning. In a standard educational context, it would be preferable to deploy games that can deliver benefits to the students quickly, without a long introduction or tutorial phase. However, for research purposes it would be a step forward to control some of the variables that we suspect might be having an influence. In addition, while conducting such experiments in future, it could be helpful to capture the gameplay, for example by recording video of the screen. This would help to determine the extent to which players were able to make meaningful progress in their games. We only captured a few videos, as an extra check; but that was already useful to do, and so we recommend experimenters to capture them all in case they need to analyse them afterwards.

The question of game genre is worth consideration. We made sensible choices, of a typical sandbox, puzzle, and other action (FPS) game. But there is no standard score for typical game genres that can be generally used for scientific purposes, and many games inhabit multiple genres at once. It may one day be worth starting to categorise games into (cognitively significant) types, to standardise the results of experiments like these. Perhaps it would be premature to begin that now, since there is as yet little theoretical psychological foundation for any such taxonomy. However, it is something that could develop alongside a growing understanding of the possible mental factors that may be able to account for the effects of game-play on creativity.

Some research questions that suggest themselves therefore include: the different types of game that may affect creativity; what types of creativity; how and why; and for how long? Is emotion or mood the intervening factor, in the sense of positive or negative affect; and if so is player choice of game crucial to getting positive results? Is flow the most important intervening factor, as a particular emotional-cognitive state? Some progress has been made on these questions in the present study; but it really only represents an encouraging start, and it raised more questions than it answers. It may yet turn out that the study of creativity affected by game-play could throw some much-needed light on the underlying psychological mechanisms that could account for the effects; and thus, regenerate creativity theory. 


\section{RELATED WORK}

In the last year or two, there has been an increase in the publications about video games and creativity. A slightly earlier publication by Jackson et al (2012) is already influential, and has attracted a lot of attention in the popular press, for its survey showing that video game players seem to be more creative. It has been cited in literature surveys about the benefits of video games: including by Granic et al (2014), who point out however, that as a consequence of the type of survey that was done, the result is only a correlation. The need for more experimental studies, such as the present one, has been noted by other researchers too. Bowman et al (2015) called for this kind of research, for example, when they assert that, "there has been scant work specifically aimed at studying the impact of video games on fostering creativity in people - with only a handful of studies on the topic since 2010." They also suggest that video game genres may differ in their effects, and that the emotional feel of a game may also be significant.

We agree that it is necessary to conduct controlled experimental studies into these questions, in order to take us beyond the preparatory field work that first noted the association between games and creativity (as above, by Jackson et al, 2012). The present study embarks on this line of experimental research. However, it would also be interesting to go back into that kind of survey work, which Jackson et al conducted, and investigate the types of games that (more) creative people choose to play. Since we find that different types of game affect creativity differently, it might also be the case that some of them would be preferred, and chosen because of these effects.

Experimental work in this connection typically turns on the concept of flow (Csikszentmihalyi, 1996; Abuhamdeh et al, 2015). For example, Blanco-Herrera et al (2015) recommend video games as a way to induce flow, to stimulate and train creativity; and they particularly suggest Minecraft as suitable sandbox game for the purpose. In that, they go as far as to indicate why it might be helpful. Creativity requires novelty, but also criticism of any new ideas, and they point out that the game does test the strength of players' ideas, such as by having monsters that come along and try to destroy their constructions during the night. Because that feedback would often occur when the player is off-line, it is not very helpful to stimulating a mental state of flow in the player; but there is another problem with Minecraft that is suggested by the present study. Namely, it can be frustrating to players, and that might have both good and bad effects. While it may challenge some players to work harder to learn faster and perform better, and so motivate greater problem solving abilities; it may also induce negative affect that could undermine any sense of flow, and thus creativity.

Emotions are sometimes seen as a significant connection between play and creativity in other ways too; not only via the concept of flow. Fredrickson's "broaden and build" theory is that positive affect releases the person to adopt a more open attitude, and explore the environment or problem, for example (2013). This theory is picked up by Jackson \& Games (2015), who point out that video games can induce positive emotions, and this might be a route to encouraging more exploratory thinking styles. The matter is subtler though, and they also note that games can induce frustration as well, and other negative emotions. Their interesting suggestion here is that games may train people to regulate their emotions more, as they always offer success if players will only try harder and persist for long enough. Games also demonstrate to players that failing to control their own negative emotions can worsen their performance. This suggests an intriguing possibility to us, if we observe that the creative process in itself is often felt to be a tense, and sometimes even fraught experience. The ability to persist at the task despite difficulties and self-doubt is a mark of the creative personality, and often remarked upon in biographies of the most famously creative people. Could it be that play is effective training for the personality: for emotion management, and resilience in the face of adversity?

Bowman et al (2015) touch upon the importance of play, which they see as a creative process in its own right. Playful thinking encourages exploration, the construction and testing of new ideas; 
which would be discouraged when there are important goals to pursue under time-pressure or other constraints. Whilst we agree with this perspective, there's an implied threat as well. For it remains an open question whether creativity, if awakened in a game context, would transfer to subsequent activities. For one thing, if those are goal-oriented activities in themselves, reapplying pressure again, then why should the creative state of mind survive the transition?

Another theoretical question about the domain-generality of creativity also comes into play here. Baer (2016) makes the case that creativity is not as general as it is typically supposed to be, and that evidence shows it may be largely specific to the relevant domain in some ways. He notes that this has important implications for theory; for measuring; and for training of creativity. The present study throws another light on the question, as the experiment design can only work at all under the assumption that the creative state of mind can indeed transfer to another domain. In particular, it is induced by playing some video game; and transfers to the TTCT testing context, in which the player is asked to think up unusual uses for everyday objects, and so on. To the extent that works, it indicates that there may well be domain-general factors in creativity.

Finally, we are not aware of any research in the areas of creativity that pick apart the several strands that are measured by different versions of psychometric tests. In particular, it would be good to hear about more research that examines ways in which certain types of creativity (such flexibility, in our case) are stimulated more significantly. That could then stimulate deeper theoretical understanding in turn. At present, however, this remains a call for further research.

\section{CONCLUSION}

In this experiment to investigate any effects of different sorts of video games on creativity, players were tested for creativity before and after playing one of three games. The hypothetically least creative type of game (the FPS game) had more effect than the sandbox game. It is possible that intervening emotional states caused some disruption to the results. In future work it would be a good idea to control for mood state changes, especially as games can be emotional experiences.

More curiously, the most significant results here differentiated between forms of creativity. While fluency and originality were not much affected in this experiment, creative flexibility was. This seems an odd result, which deserves further research to resolve the contradiction.

Although players developed greater flexibility, in particular, they had little or no change in fluency or even originality in their ideas. Further work should be done to try and replicate this result, and then to try and account for why different types of creativity should respond differently to playing a video game.

Implications for education are that some types of video game have a potential use in priming the flexibility of the students. That refers to their ability to generate examples of concepts that are related but also quite different from each other. It is a kind of thinking that should help students to avoid falling into fixed or habitual thought patterns. This is surely useful for learning, in cases where new concepts need to be formed and there is less need for rote learning of material.

Results also showed that player familiarity with and enjoyment of the game were other key variables. In order to use this approach in a classroom situation, therefore, the students would first need to learn how to play the game, if they have not played it or a similar game in the past. Otherwise they are apt to get frustrated and that would interfere with the experience of flow, which could in turn hamper the desired beneficial effects.

While the effects found in this study were only temporary, as far as we know, we propose that a longer term change might be indirectly brought about. Namely: students might develop greater confidence in their creative ability if it is exercised immediately after playing the game. Such an improvement in their attitude and self-knowledge would then be the true lasting benefit of the 
intervention. Finally, it is also possible that playing the relevant games more often, and over a longer period, could sustain a deeper change in the player's creativity, both stronger and more durable. It would need further research to confirm that.

We conclude that, depending on genre, video games can affect temporary levels of creativity, but the connection is not a simple one. The highly-differentiated effects on forms of creativity, that appear to be only subtly different, is the most provocative finding here. In particular, it remains a puzzle why the measure of flexibility should be so much more susceptible than the others, to the game-play experience. 


\section{REFERENCES}

Abuhamdeh, S., Csikszentmihalyi, M., \& Jalal, B. (2015). Enjoying the possibility of defeat: Outcome uncertainty, suspense, and intrinsic motivation. Motivation and Emotion, 39(1), 1-10. doi:10.1007/s11031-014-9425-2

Alpaugh, P. K., \& Birren, J. E. (1977). Variables Affecting Creative Contributions across the Adult Life Span. Human Development, 20(4), 240-248. doi:10.1159/000271559 PMID:903112

Amabile, T. M. (1985). Motivation and creativity: Effects of motivational orientation on creative writers. Journal of Personality and Social Psychology, 48(2), 393-399. doi:10.1037/0022-3514.48.2.393

Amabile, T. M. (1996). Creativity in context: Update to the social psychology of creativity. Boulder, CO: Westview Press.

Baer, J. (2016). Domain Specificity of Creativity. Academic Press.

Blanco-Herrera, J. A., Groves, C. L., Lewis, A. M., \& Gentile, A. (2015). Teaching Creativity: Theoretical Models and Applications. In G. Green \& J. C. Kaufman (Eds.), s), Video Games and Creativity (pp. 139-158). Academic Press. doi:10.1016/B978-0-12-801462-2.00007-2

Bowman, N. D., Kowert, R., \& Ferguson, C. J. (2015). The Impact of Video Game Play on Human (and Orc) Creativity. In G. Green \& J. C. Kaufman (Eds.), s), Video Games and Creativity (pp. 39-60). Academic Press. doi:10.1016/B978-0-12-801462-2.00002-3

Cohen, P. (2010, May 16). How do you measure creativity?; scientists rethink the definition of the word as they try to figure out how the brain works. Edmonton Journal.

Csikszentmihalyi, M. (1996). Creativity: Flow and the psychology of discovery and invention. New York: HarperCollins.

Fredrickson, B. L. (2013). In E. Ashby Plant \& P. G. Devine (Eds.), Positive emotions broaden and build (Vol. 47, pp. 1-53). Advances in experimental social psychology Academic Press.

Glass, B. D., Maddox, W. T., \& Love, B. C. (2013). Real-Time Strategy Game Training: Emergence of a Cognitive Flexibility Trait. PLoS ONE, 8. PMID:23950921

Granic, I., Lobel, A., \& Engels, R. C. M. E. (2014). The Benefits of Playing Video Games. The American Psychologist, 69(1), 66-78. doi:10.1037/a0034857 PMID:24295515

Guilford, J. P. (1967). The nature of human intelligence. New York: McGrawHill.

Jackson, L. A., \& Games, A. I. (2015). Video Games and Creativity. In G. Green \& J. C. Kaufman (Eds.), s), Video Games and Creativity (pp. 3-38). Academic Press. doi:10.1016/B978-0-12-801462-2.00001-1

Jackson, L. A., Witt, E. A., Games, A. I., Fitzgerald, H. E., von Eye, A., \& Zhao, Y. (2012). Information technology use and creativity: Findings from the Children and Technology Project. Computers in Human Behavior, 28(2), 370-376. doi:10.1016/j.chb.2011.10.006

Kaufman, C. J., Plucker, A. J., \& Baer, J. (2008). Essentials of Creative Assessment. John Wiley \& Sons Inc.

Lubart, T. I., Mouchiroud, C., Zenasni, F., \& Averill, J. R. (2004). Links between creativity and aggression. International Review of Social Psychology, 17(12), 145-176.

Millar, G., \& Dahl, C. (2011). The Power of Creativity. ATA Magazine, 91(3), 16-21. Retrieved from https:// www.teachers.ab.ca/Publications/ATA\%20Magazine/

Neumeister, K. L. S., \& Cramond, B. (2004). E. Paul Torrance (19152003). The American Psychologist, 59(3), 179. doi:10.1037/0003-066X.59.3.179

Pitri, E. (2013). Skills and Dispositions for Creative Problem Solving during the Artmaking Process. Art Education, 66(2).

Silvia, P. J., Martin, C., \& Nusbaum, E. C. (2009). A snapshot of creativity: Evaluating a quick and simple method for assessing divergent thinking. Thinking Skills and Creativity, 4(2), 79-85. doi:10.1016/j.tsc.2009.06.005 
Sternberg, R.J. (2006). Creating a vision of creativity: The first 25 years. Psychology of Aesthetics, Creativity, and the Arts, (1), 2-12.

Treffinger, D. J. (2009). Myth 5: Creativity is too difficult to measure. Gifted Child Quarterly, 53(4), 245-247. doi: $10.1177 / 0016986209346829$

Vidal, R. V. (2009). Creativity for problem solvers. AI \& Society, 23(3), 409-432. doi:10.1007/s00146-007-0118-1

David Moffat's degrees in mathematics and computer science, were from Cambridge and Canterbury universities. After a time in the software industry he went to research Al at Edinburgh, and psychology at Amsterdam and Cardiff, then lecturing computing at GCU. He teaches game design and affective computing; and researches Al and emotion, creativity in education, serious games, and cognitive science.

William Crombie studied Computer Games Design at Glasgow Caledonian University. With a long-term fascination in games, both digital and non-digital, he developed his research interests while studying in Glasgow, into why we play games; what benefits we gain from them; and how we can use video games to enhance player skills outside of the game. Although taking a year away from study, to coach young people in the noble martial art of fencing, he remains a loyal participant in the Scottish Game Jam which is held annually at the university; and where he is returning in order to continue his studies with a Master's degree.

Olga Shabalina is an Associate Professor at Volgograd State Technical University, in the Department of Computer Aided Design. Her research interests are in education research, including how best to teach engineering subjects, using technology enhanced learning in general. She is particularly interested in the application of game-based learning to the higher education curriculum. Her contributions to the field include research on the development and measurement of creativity in undergraduate students, and the use of games to stimulate creativity. She has chaired tracks in these areas at the ECGBL in recent years. 


\title{
Call for Articles
}

\section{International Journal of Game-Based Learning}

\author{
Volume 7 • Issue 2 • April-June 2017 • ISSN: 2155-6849 • eISSN: 2155-6857 \\ An official publication of the Information Resources Management Association
}

\section{MISSION}

The mission of the International Journal of Game-Based Learning (IJGBL) is to promote knowledge pertinent to the design of Game-Based Learning environments, and to provide relevant theoretical frameworks and the latest empirical research findings in the field of Game-Based Learning. The main goals of IJGBL are to identify, explain, and improve the interaction between learning outcomes and motivation in video games, and to promote best practices for the integration of video games in instructional settings. The journal is multidisciplinary and addresses cognitive, psychological and emotional aspects of Game-Based Learning. It discusses innovative and cost-effective Game-Based Learning solutions. It also provides students, researchers, instructors, and policymakers with valuable information in Game-Based Learning, and increases their understanding of the process of designing, developing and deploying successful educational games. IJGBL also identifies future directions in this new educational medium.

\section{COVERAGE AND MAJOR TOPICS}

The topics of interest in this journal include, but are not limited to:

Adaptive games design for Game-Based Learning - Design of educational games for people with disabilities - Educational video games and learning management systems $\bullet$ Game design models and design patterns for Game-Based Learning • Instructional design for Game-Based Learning • Integration and deployment of video games in the classroom • Intelligent tutoring systems and Game-Based Learning $\bullet$ Learning by designing and developing video games $\bullet$ Learning styles, behaviors and personalities in educational video games $\bullet$ Mobile development and augmented reality for Game-Based Learning $\bullet$ Motivation, audio and emotions in educational video games $\bullet$ Role of instructors $\bullet$ Virtual worlds and Game-Based Learning

\section{ALL INQUIRIES REGARDING IJGBL SHOULD BE DIRECTED TO THE ATTENTION OF:}

Patrick Felicia, Editor-in-Chief•IJGBL@igi-global.com

ALL MANUSCRIPT SUBMISSIONS TO IJGBL SHOULD BE SENT THROUGH THE ONLINE SUBMISSION SYSTEM: http://www.igi-global.com/authorseditors/titlesubmission/newproject.aspx

IDEAS FOR SPECIAL THEME ISSUES MAY BE SUBMITTED TO THE EDITOR(S)-IN-CHIEF

\section{PLEASE RECOMMEND THIS PUBLICATION TO YOUR LIBRARIAN}

For a convenient easy-to-use library recommendation form, please visit: http://www.igi-global.com/IJGBL 